\title{
Teacher Professional Development and Student Achievement in a Developing Country
}

\author{
Matthieu W. Yangambi \\ Department of Pedagogy, National Teaching University, Kinshasa, Ngaliema, Democratic Republic of the Congo \\ Email: matthieuwy12@gmail.com
}

How to cite this paper: Yangambi, M. W. (2021). Teacher Professional Development and Student Achievement in a Developing Country. Creative Education, 12, 2283-2300. https://doi.org/10.4236/ce.2021.1210173

Received: August 18, 2021

Accepted: October 11, 2021

Published: October 14, 2021

Copyright $\odot 2021$ by author(s) and Scientific Research Publishing Inc. This work is licensed under the Creative Commons Attribution International License (CC BY 4.0).

http://creativecommons.org/licenses/by/4.0/

\begin{abstract}
Teacher professional development is a common practice used in developed countries. With the ongoing pressure on educators to improve student achievement, teacher continual professional development becomes an obligation for school systems that are committed to improving student achievement. The purpose of this research paper was to find out how important and valued elementary teachers and school administrators find the practice of teacher continual professional development and whether the cost related to the practice can hinder the initiative. This research was conducted in a number of elementary schools in Kinshasa, the Capital of the Democratic Republic of the Congo. The sample $(\mathrm{N}=108)$ was based on the non-probability sampling technique known as convenience sampling from elementary school teachers and principals. The questionnaire was designed based on the literature related to importance of continual teacher professional development and student achievement. Findings were of importance. First, teachers agree on the importance of teacher continual professional development for student achievement. However, they indicate that they do not apply what is recommended. Teachers and principals agree that continual teacher professional development is very important but costly to schools. They also indicate that the cost is not a deterrent to the use of the practice. The result of this study may inform education policy makers and school systems in this country about the necessity to fund projects related to teacher continual professional development if they intend to improve student achievement.
\end{abstract}

\section{Keywords}

Teachers, Continuing, Professional, Development, Inservice, Students, Achievement 


\section{Introduction}

This work is part of the perspective of adult education, particularly the in-service training of elementary school teachers. It was conducted in number of elementary schools in the large City of Kinshasa, the Capital of the Democratic Republic of the Congo. Adult education aims to learn how to learn better in order to change, improve, perfect, elevate or evaluate knowledge, methods or techniques for dynamic progress and specially to improve student achievement.

In-service teacher training provides opportunities to acquire new techniques and adapt to new situations. It allows teachers to acquire skills and knowledge. An adult or teacher is not an older child. Even if his continuing education is aimed at filling the gaps in instruction, a teacher is a civil servant who already has a job or experiences that motivate him and make him perceive things differently. A teacher is a person who has entered professional life. He /she is a manager who already has professional experience.

School is a social institution in excellence. It is an environment for communication and/or the transmission of knowledge, skills and positive attitudes. The problem of education is very important for any country that aspires to development. The development in question must be social, cultural, intellectual and economic at the same time, and neglecting the education sector can keep a nation underdeveloped.

In today's world, education for all occupies a special place in the various policies adopted by most countries, especially developing countries. According to the World Bank report (2014: p. 130), "education systems are experiencing service delivery problems in general". The fact that schools are accessible for some, the dysfunction of schools also undermines that of society in general. The education of students or children in general and in particular that of adults have been a concern for researchers for centuries.

\subsection{Problem Statement}

We note that schools organize in-service training for their teachers in order to accompany them, to supervise them and to obtain a better academic performance for all students. We reflect on appropriate strategies and methods that should facilitate this in-service teacher training.

Our main concern is whether continuing training is well organized in their respective schools? Does it meet the needs, interests and expectations of teachers? What would be the annual cost of in-service teacher training? Would this cost be so exorbitant as to minimize or simply suppress in-service teacher training?

This research is driven by our empirical observation that teacher delivery no longer results in improved student achievement. It is a question of whether inservice teacher training is necessary or is it organized effectively.

\subsection{Research Questions}

This research concerns the in-service training of elementary school teachers in 
number of The Catholic Convention Schools in Kinshasa. For this, it should be noted that a teacher in office needs support, supervision and continuous training throughout his career. This continuous training will allow him to increase his scientific or intellectual level. It could improve its level of performance by making it more professional. The following questions are the main concerns of this research:

- What is the impact of in-service training of primary school teachers on student achievement?

- What is the cost associated with in-service teacher training?

\subsection{Importance of This Study}

The aim of this study is to determine whether continuing education has a positive influence on student performance. In undertaking this research, our objective is twofold:

- To determine the impact of in-service teacher education on student achievement.

- To evaluate or assess the cost of training in relation to student achievement.

We chose this topic to understand the impact and/or effectiveness of in-service training for elementary school teachers on student achievement. We will investigate a number of Catholic convention schools in Kinshasa. Teachers' performance can have a negative or positive impact on student achievement. The results of this research could determine the impact of teachers continuing education on student achievement.

\subsection{Limitations}

Due to the single sample available for the study, the result may not be generalizable beyond the specific population from which the sample was drawn.

\subsection{Delimitations}

Given the academic and socio-economic constraints, our study covers the period from January 2021 to August 2021. In order to manage the data collected, the instruments used only multiple-choice questions using the Likert scale and few direct questions relating to the cost of in-service teacher training.

\subsection{Plan of Work}

Our research focuses on four (5) chapters:

1) The first chapter focuses on the Introduction.

2) The second chapter deals the Revision of the Literature.

3) The third chapter explains the Methodology of the work.

4) The fourth chapter presents Analysis, Results and Findings.

5) The fifth chapter sets out Summary, Conclusion and Recommendation.

\section{Revision of the Literature}

\subsection{Introduction}

According to the British Education Suppliers Association (BESA, 2017), on its 
online "Insights" publication of 3 July 2017, we put together a list of the main benefits that continuing professional development (CPD) can offer teachers, highlighting how important it is:

Getting up to date with the evolution of the industry.

Teaching methods are continuously developing and continuing professional development (CPD) gives teachers the opportunity to learn new techniques and strategies that allow them to keep up with colleagues who have just completed their training.

Student interaction skills

CPD gives teachers the opportunity to reinforce existing skills as well as learn new ones that were not covered during teacher training.

Practice makes perfect

Teachers can use the same type of simulation training to improve classroom management and interaction with challenging students in a specified environment.

\subsection{Effective Professional Development of Teachers}

According to Darling-Hammond, Hyler and Garner (2017), for students to develop mastery of the subjects taught, problem-solving practices, good ways of communication and effective collaboration, teachers need to use more sophisticated forms of teaching. These researchers reviewed 35 methodologically rigorous studies that demonstrated a positive link between teacher professional development, teaching practices and student outcomes. They identified the key characteristics that determine the effectiveness of continuing professional development. These key features are necessary and indispensable in order to inform education leaders and policy makers who are constantly looking for best professional development practices to enhance student learning. According to these researchers, effective professional development is essential to learning and perfecting the pedagogies needed to teach these skills.

\subsection{Defining and Studying Effective Professional Development}

Darling-Hammond, Hyler and Garner (2017) define effective professional development as structured professional learning that leads to changes in teacher practices and improved student learning outcomes. These researchers reviewed studies that met their methodological criteria that have emerged from their extensive literature research over the past three decades.

Using this methodology, they found that effective professional development incorporates most of the following:

- Is the content focused on professional training that focuses on teaching strategies associated with specific curriculum content that supports teacher learning in the context of classroom teachers?

- Integrates active learning: Active learning directly engages teachers in designing and testing teaching strategies, giving them the opportunity to en- 
gage in the same learning style they design for their students.

- Supports collaboration: High-quality continuing professional development (CPD) creates a space where teachers can share ideas and collaborate in their learning, often in employment-integrated contexts.

- Offering expert coaching and support: Coaching and expert support involves sharing expertise on evidence-based content and practices, focused directly on the individual needs of teachers.

- Offers feedback and reflection: High-quality professional learning often allows teachers to reflect, receive feedback, and make changes to their practice by facilitating reflection and soliciting feedback.

- Is of extended duration: An effective CPD gives teachers sufficient time to learn, practice, implement and reflect on new strategies that facilitate changes in their practices.

\subsection{Creating the Conditions for Effective Professional Development: Opportunities and Challenges.}

Research has established that the education system in which CPD occurs has implications for its effectiveness. Specifically, teaching and learning conditions at school and at the system level can inhibit the effectiveness of the CPD. For example, insufficient resources for $\mathrm{CPD}$, including necessary teaching materials, frequently exacerbate inequalities and hinder educational improvement efforts (Darling-Hammond, Hyler, \& Garner, 2017).

\subsection{Implications for Policy and Practice}

Examples of CPD that have been successful in improving student achievement can help policymakers and practitioners better understand what quality professional learning looks like for teachers. According to Darling-Hammond, Hyler and Garner (2017), recommended actions for decision-makers to support and encourage effective ongoing professional development are:

1) Adopt professional development standards to guide the design, assessment and funding of professional learning for educators.

2) Conduct regular needs assessments using staff survey data to identify areas of professional learning most needed and desired by educators.

3) Identify and train expert teachers as mentors and coaches to support learning in their area of expertise for other educators.

4) Integrate professional learning into the academic improvement initiatives of the Student Success Act, such as efforts to implement new learning standards, use student data to inform teaching, improve student literacy, increase students' access to advanced courses, and create a positive and inclusive learning environment.

5) Offer flexible funding and continuing education units for learning opportunities that include sustained engagement in collaboration, mentoring and coaching, as well as institutes, workshops and seminars. 


\subsection{Role of Continuous Professional Development of Teachers in Educational Change}

Almost all teachers face a number of challenges when implementing an education reform. In order to have a successful implementation process, it is important to consider changes in teaching and learning processes before introducing educational innovation (Ucana, 2016). As Fullan (2016: p. 97) argues that "educational change depends on what teachers do and think", the role of teachers and in particular their continuing professional development (CPD) have to be taken into account in the implementation of any education reform. According to Bell and Gilbert (2005), teacher development is an ongoing process. Teachers are always looking for new ways and methods to improve their students' learning.

During the Continuing Professional Development (CPD) process, teachers gain a new understanding of teaching and learning, new beliefs, new teaching methods and new materials for student learning, as well as the ability to develop not only professionally, but also socially and personally. As is the case with most teachers, they also encounter many of the blockages they face before achieving successful professional development (Ucana, 2016).

Research undertaken by Ucana (2016) demonstrates the importance of the role of teachers' CPD in the implementation of reforms, such as the new curriculum and the role that school culture plays in teachers' CPD.

The idea that teachers play a key role in the implementation of education reform is no longer a controversial issue. The mission of teachers is very important to bring about change in education because they have to decide whether or not they accept the change.

In addition to this, they mention three imperatives that can be considered as a function of teachers' CPD. The first imperative is to align teachers' practice with educational policies; the second is to help teachers improve their performance in order to improve student learning and outcomes; and the last is to improve the prestige of the teaching profession.

In the $21^{\text {st }}$ century, teachers' CPD is increasingly encouraged by governments around the world, as it is seen as indispensable for meeting the ever-changing needs of students in today's schools (Swafford, 2000).

Whatever the reason for educational change, teachers themselves find themselves in positions of being both "the subject" and the "agent of change" (Sikes, 2013). On the one hand, teachers have important tasks to accomplish and implement innovations, on the other hand, they are also required to make changes in their beliefs, attitudes, knowledge and skills, and more importantly in their teaching practices.

In the existing literature, the evidence is that teachers' $\mathrm{CPD}$ and educational changes are recognized as highly interdependent and have a crucial function in determining success and improvement of teaching. In order to better understand this relationship, educators need to be aware of the factors that influence the implementation process undertaken by teachers (Ucana, 2016). 


\subsection{School Culture}

School culture can be defined as "the basic assumptions, norms and values, and artifacts that are shared by school members that influence their functioning" (Maslowski, 2001: pp.8-9). In the literature, many scholars recognize the importance of school culture in creating the circumstances in which educational innovations can flourish and become constant. Day and Sachs (2004), emphasize the importance of school culture for teacher learning.

In addition to change at the individual level, Fullan (2016) emphasizes the importance of organizational change to provide support and stimulation to encourage teachers to change their practices.

\section{Methodology}

\subsection{Introduction}

The purpose of this study was to evaluate the in-service training of elementary school teachers in a number of schools in Kinshasa, the capital of the Democratic Republic of the Congo. Two concerns were examined:

1) What is the impact of in-service training of primary school teachers on student achievement?

2) What is the cost associated with in-service teacher training?

\subsection{Research Design}

This study was the subject of quantitative research to analyze data collected from a questionnaire designed specifically for this study (Appendix A). Surveys collect data using two basic methods, interviews and questionnaires, each with two options for administration: remote or direct. The procedure allows for four different possible approaches to data collection: personal interview, telephone interview, mail-in questionnaire, and directly administered questionnaire (Ary, Jacobs, \& Razavieh, 1996). We chose to use the directly administered questionnaire for its high response rate, which typically reaches one hundred percent. Other advantages of this method are the low cost and the fact that the researcher is present to provide help or answer respondents' questions. This type of survey is administered to a group of participants gathered at a designated location for specific purposes (Ary, Jacobs, \& Razavied, 1996). For this study, which focused on in-service teacher training and the cost involved, the direct approach offered the highest possible participation rate of the four methods.

Quantitative analysis is used to describe and predict, corroborate and confirm, and experiment with hypotheses. It offers familiar variables, accepted guidelines and an unchanged format, and is generally objective and environment-independent. This is typically a large sample using standardized methods of data collection and deductive analysis. The results were approached objectively, using figures, statistics and summative data (Gall, Borge, \& Gall, 1996; Leedy \& Ormrod, 2001). 


\subsection{Sample}

The target population was identified as teachers and principals of number of elementary schools in Kinshasa, the capital of the Democratic Republic of the Congo. The accessible population was selected based on the interest of the research, based on non-probability sampling known as convenience sampling. The questionnaires were submitted to the school management and each available teacher or principal came to answer the questionnaire. The researcher chose to use data from the 108 participants $(\mathrm{N}=108)$ who volunteered for the research.

The researcher used the convenience sampling technique to circumvent the lack of accessibility to other schools as well as the availability and cooperation of some teachers and principals.

\subsection{Instrumentation}

The data collection method in this study was the questionnaire (Appendix A), which was validated before use (Gall, Borg, \& Gall, 1996). The questionnaire has been designed in such a way that teachers and principals can understand it and respond appropriately. In addition, the questionnaire has been designed to encompass components of the involvement of in-service teacher training and the financial cost of such training. This questionnaire was based on research that led to higher student achievements. The questionnaire consisted of two parts. The first part concerns the importance or otherwise of in-service teacher training; the second concerns the cost involved in teacher training.

In order to collect data useful for the evaluation of the research questions, the questionnaire used a Likert scale. The results of the Likert rating (i.e. 1 to 15) revealed the relative importance of each component of each research question.

\subsection{Data Collection}

The researcher established contact with primary school principals and distributed the survey questionnaires (Appendix A). The study was conducted in number of elementary schools in Kinshasa. Sample $(\mathrm{N}=108)$ was obtained by voluntary participation. The questionnaire was distributed to teachers and to their school principals. They were asked to respond voluntarily and anonymously. The questionnaire was administered in the morning, from 8:00 a.m. to 1:00 p.m. and supervised by the researcher. Responses to the questionnaire provided information on all research questions.

\subsection{Data Analysis}

The aim of this study was to evaluate or not the importance of in-service teacher training and the cost of training. To answer the research questions, a questionnaire was administered to respondents (Appendix A). Data were collected from the total sample of respondents. Descriptive statistics such as means and standard deviations were calculated for the survey items. Data were collected to answer the research questions. Means and standard deviations for each element of 
each research question were calculated.

Data collected to answer the first research question (what is the impact of in-service training of primary school teachers on student achievement) were pooled. Means and standard deviations were used to analyze the data. The averages for each survey question were organized in descending order.

To answer research question number two (what is the cost associated with in-service teacher training), averages and standard deviations were used to analyze the data. The averages for each survey question were organized in descending order.

\subsection{Limitations}

The study relied on the little science available on the professional development of primary school teachers. Few research studies exist that deal with this topic. A Likert-scale assessment provided data considered valuable, but responses in the middle of the range were difficult to interpret.

\section{Analysis, Results, and Findings}

\subsection{Introduction}

The aim of this study is to assess the importance of in-service teacher training and the cost of it. The questionnaire distributed to participants was tested by a number of teachers and principals who did not participate in this study. They tested the questionnaire to assess the understanding, readability and validity of the content related to this study.

This chapter presents an analysis of the data collected from the questionnaire administered to 108 teachers and principals of number of elementary schools in Kinshasa. Data were collected to answer the following research questions:

- What is the impact of in-service training of primary school teachers on student achievement?

- What is the cost associated with in-service teacher training?

Descriptive statistics (means and standard deviations) were used to analyze the data collected during the administration of the questionnaire.

\subsection{Analysis}

The researcher grouped the results into two categories related to the research questions. Due to the lack of statistical software available, the researcher used manual calculation from one of the web sites such as (easycalculation.com) to produce the data on which the following analyses are based. The data requested to answer the research questions were organized using descriptive statistics (means and standard deviation). Interviewed teachers and principals indicated their answers to the research questions using the Likert scale.

\subsubsection{First Research Question}

What is the impact of in-service training of primary school teachers on student 
achievement?

The teachers surveyed indicated their answers to the first research question regarding the impact of continuing education on student achievement using the Likert scales 1 to 5 ( 1 being absolutely not approved to 5 fully approved). The responses to items 1 to 15 answered the first research question. The average and standard deviations of each element were calculated. The averages in descending order and the standard deviations for items 1 to 15 determined how consistent or not the teachers surveyed were in their responses.

Table 1 presents the descriptive statistics for the items surveyed according to ranked averages and standard deviations by proposals answering questions 1 to 15.

According to Table 1, teachers generally agree that points (1) to (13) are of great importance and have responded consistently with standards deviations below 1.00 for items (1) to (10). With items (1) to (10), teachers highly recognize the importance of CPD. Items (11) to (14) show some inconsistencies among

Table 1. Impact of in-service training of primary school teachers on student achievement presented in order of magnitude of averages.

\begin{tabular}{|c|c|c|}
\hline Assertions & $\begin{array}{l}\text { Averages } \\
\underline{\mathbf{M}}\end{array}$ & $\begin{array}{l}\text { Deviations } \\
\quad \text { SD }\end{array}$ \\
\hline (1) Continuing professional development is essential for my career. & 4.43 & 0.85 \\
\hline $\begin{array}{l}\text { (14) Continuous and effective professional development gives teachers sufficient time to learn, practice, implement and } \\
\text { reflect on new strategies that facilitate changes in their practice. }\end{array}$ & 4.41 & 0.67 \\
\hline (2) The continuous professional development of teachers helps to improve student achievement. & 4.38 & 0.65 \\
\hline (3) Continuous professional development gives teachers the opportunity to be up to date with new technologies. & 4.35 & 0.88 \\
\hline (4) Continuing professional development allows teachers to hone knowledge not learned during training. & 4.33 & 0.90 \\
\hline (5) Continuous professional development teaches teachers professional practices to make them continually competent. & 4.32 & 0.88 \\
\hline (6) Continuing Professional Development increases teachers' motivation, confidence and commitment to teaching. & 4.30 & 0.92 \\
\hline $\begin{array}{l}\text { (7) Effective professional development is essential to learning and developing the pedagogies needed to teach these } \\
\text { skills. }\end{array}$ & 4.30 & 0.90 \\
\hline $\begin{array}{l}\text { (8) Continuing professional development is program-based that focuses on teaching strategies associated with specific } \\
\text { curriculum content that supports teacher learning in the context of classroom teachers. }\end{array}$ & 4.29 & 0.91 \\
\hline $\begin{array}{l}\text { (10) High-quality professional development creates a space where teachers can share ideas and collaborate in their } \\
\text { learning, often in contexts integrated with employment. }\end{array}$ & 4.25 & 0.87 \\
\hline $\begin{array}{l}\text { (11) Continuing professional development gives teachers opportunities to view templates that include lesson plans, unit } \\
\text { plans, student work examples, peer teacher observations, and video or written teaching cases to immerse } \\
\text { themselves in a clear vision of what best practices look like. }\end{array}$ & 4.13 & 1.07 \\
\hline $\begin{array}{l}\text { (12) Through continuing professional development, teachers benefit from expert assistance and support that involves } \\
\text { sharing expertise on evidence-based content and practices, focused directly on the individual needs of teachers. }\end{array}$ & 4.11 & 1.03 \\
\hline $\begin{array}{l}\text { (13) High-quality professional learning often allows teachers to reflect, receive feedback, and make changes to their } \\
\text { practice by facilitating reflection and soliciting feedback. }\end{array}$ & 4.11 & 1.04 \\
\hline $\begin{array}{l}\text { (14) Active learning directly engages teachers in designing and testing teaching strategies, giving them the opportunity } \\
\text { to engage in the same learning style they design for their students. }\end{array}$ & 3.80 & 1.07 \\
\hline (15) In my school, we practice the 14 points set out above quite often. & 3.67 & 0.96 \\
\hline
\end{tabular}


teachers. Item (11) is related to teaching preparation or lesson plan; item (12) is related to learning for improvement; item (13) is related to learning cooperation; and item (14) is related to improving teaching strategies. These inconsistencies can determine that $\mathrm{CPD}$ provided to teachers are not well focused to these specific points. Item 15 shows the least of the means with consistency in the answers.

It should be noted that item (15) which summarizes the other points surveyed, has the lowest average with remarkable consistency. This is in direct contradiction with the approvals of the teachers surveyed, which indicate high averages and fairly notable consistency.

Understanding teachers' responses shows us that teachers recognize the value and the importance of continuing professional development in their careers but do not make use of what they learn in these in-service trainings as expressed in items $11,12,13$, and 14 .

\subsubsection{Second Research Question}

What is the cost associated with in-service teacher training?

According to the data collected, $66 \%$ of respondents indicate that their schools offer professional development every year; $19 \%$ every two years and $16 \%$ every five years. These data show that schools are not compatible with providing professional development to teachers every five years.

Given the cost associated with continuing professional development, $100 \%$ of respondents indicated that the cost would be enormous and noted the need to hire a qualified consultant.

None of the respondents mentioned that the higher cost of teacher professional development could discourage initiatives.

With respect to the question regarding the need for ongoing professional development of teachers, all respondents indicated that there was a need to provide professional development to all members on a regular and ongoing basis, i.e., every 5 years. (Tables 2-5)

\subsection{Observations and Interpretations}

Responses to the questionnaire generated data that answered both research questions. Table 1 and others presented above gives a particular overview of all the issues studied. The responses that have been analyzed for their overview of

Table 2. Question \#16: At my school, we have opportunities for ongoing professional development.

\begin{tabular}{cccc}
\hline Respondents & Yes & No & Percentage \\
\hline Every year & 63 & 33 & $66 \%$ Yes \\
Every two years & 18 & 78 & $19 \%$ Yes \\
Every five years & 15 & 81 & $16 \%$ Yes \\
\hline
\end{tabular}

(Data collected from teachers' survey-Appendix A). According to the table above, $66 \%$ of teachers indicate that they have opportunities for continuous professional development each year. 
Table 3. Question \# 17: My school considers that providing professional development for teachers.

\begin{tabular}{cccc}
\hline Respondents: Teachers and Principals & Yes & No & Percentage \\
\hline Is too expensive & 72 & 36 & $67 \%$ yes \\
Would require qualified consultants & 108 & & $100 \%$ yes \\
\hline
\end{tabular}

(Data collected from teachers' survey-Appendix A). 67\% of respondents indicated that in-service professional training for teachers would be too expensive and $100 \%$ of respondents indicated that it would require qualified consultants.

Table 4. Question \# 18: The high cost of continuing professional development for teachers discourages initiative.

\begin{tabular}{lccc}
\hline & Yes & No & Percentage \\
\hline Respondents: 96 teachers and 12 principals & & 108 & 100 \\
\hline
\end{tabular}

(Data collected from teachers' survey-Appendix A). 100\% of respondents indicate that the high cost of teacher professional development does not discourage the initiative.

Table 5. Question \# 19: Is the continuous professional development of teachers essential for the teaching career? Please respond according to your position.

\begin{tabular}{cccc}
\hline Respondents & Yes & No & Percentage \\
\hline Principals. & 12 & 100 Yes \\
Teachers & 96 & 100 Yes \\
\hline
\end{tabular}

(Data collected from teachers' survey-Appendix A). Respondents indicate that the continuous professional development of teachers is essential for the teaching career.

the questions are presented below.

\subsubsection{Observations and Interpretations of the Results Concerning Research Question \# 1}

By decreasing average value, survey questions Nos. 1, 14, 2, 3, 4, 5, 6, 7, 8, 9, and

10 (Appendix 1) showed remarkable statistical recognition. The means range from 4.43 to 4.25 with standard deviations ranging from 0.65 to 0.92 . This indicates that the teachers were very consistent in their responses.

Survey questions numbers 11, 12, and 13 (Appendix 1) also have a high average of 4.11 to 4.13 but teachers are less consistent in their responses, standard deviation above 1.00

Survey question number 14 shows an average of 3.80 but teachers are less consistent in their answers, standard deviation 1.07

The last question of the survey number 15 (in my school we practice quite often the 14 points stated above), the teachers give an average of 3.67, the lowest average of all the questions surveyed and they are very consistent, standard deviation: 0.96

This crucial observation shows that teachers surveyed do not practice the necessity or usefulness of in-service professional training. These practices are indicated to be capable of improving student achievement as reported in the literature (Darling-Hammond, Hyler, \& Garner, 2017). 


\subsubsection{Observations and Interpretations of the Results Concerning Research Question \# 2}

Question \# 16: At my school, we have opportunities for ongoing professional development.

According to the table above, $67 \%$ of teachers indicate that they have opportunities for continuous professional development each year.

Question \# 17: My school considers that professional development for teachers would be too expensive and would require qualified consultants.

$67 \%$ of respondents indicated that in-service professional training for teachers would be too expensive and $100 \%$ of respondents indicated that it would require qualified consultants.

Question \# 18: The high cost of continuing professional development for teachers discourages initiative.

$100 \%$ of respondents indicate that the high cost of teacher professional development does not discourage the initiative.

Question \# 19: Is the continuous professional development of teachers essential for the teaching career? Please answer according to your professional position.

School principals and teachers surveyed indicate that the continuous professional development of teachers is essential for the teaching career.

All respondents indicated that the continuous professional development of teachers is essential for the teaching career.

From these observations, we note that teachers and school leaders value the importance of in-service teacher training. Unfortunately, this consideration is not actually practiced. Student achievement would suffer due to a lack of reasonable professional practices by school leaders.

\section{Discussions, Conclusions and Recommendations}

\subsection{Introduction}

Continuing education is one of the many important concerns in education. As we have seen in Chapter Two of this study, in-service teacher education is a critical issue not only for improving student performance, but also for improving the productive value of schools. This chapter is the culmination of what we have discovered and discussed throughout this study. It reaffirms the problem and research questions and reviews the main methodology used in the study. This chapter summarizes and discusses the results.

\subsection{Problem Statement}

This research aims to enhance or not the in-service training of teachers and the cost of these operations in the finances of schools. It is a question of determining through surveys whether the professional training of teachers could improve student achievement.

\subsection{Discussion}

The results of this study highlight several important observations that are essen- 
tial to ensure that teachers and students are equally productive. The data produced by this study shows that schools are not working to keep their faculty fit for the challenges of generations to come. The findings could suggest that school leaders take their teachers' professional training seriously if they want to continually elevate their students' achievement.

\subsection{Conclusion}

Research in the field of education is continually about finding new information to contribute to the improvement of education. To meet the challenge of running schools in the $21^{\text {st }}$ century, school leaders must be able to document themselves to serve as permanent mentors of their teachers.

\subsection{Recommendation}

If lasting changes in education are to occur and if schools are to improve students' performance or achievement, strong leadership and a skilled teaching workforce are needed (Guskey, 2000). To maintain a skilled workforce, professional teacher training must be considered paramount by any education leader.

\section{Conflicts of Interest}

The author declares no conflicts of interest regarding the publication of this paper.

\section{References}

Ary, D., Jacobs, L. C., \& Razavieh, A. (1996). Introduction to Research in Education. Harcourt Brace \& Company.

Bell, B., \& Gilbert, J. (2005). Teacher Development: A Model from Science Education. Taylor \& Francis e-Library. https://doi.org/10.4324/9780203975145

British Educational Suppliers Association (BESA) (2017, July 3). The Importance of Continued Professional Development for Teachers. BESA.

https://www.besa.org.uk/insights/importance-continued-professional-development-tea chers

Darling-Hammond, L., Hyler, M. E., \& Gardner, M. (2017). Effective Teacher Professional Development.

https://learningpolicyinstitute.org/product/effective-teacher-professional-development -report?gclid=EAIaIQobChMILWXiKrq7QIVCTKGCh181QEaEAAYAyAAEgJjifD B $\underline{\mathrm{wE}}$

Day, C., \& Sachs, J. (2004). Professionalism, Performativity, and Empowerment: Discourses in the Politics, Policies and Purposes of Continuing Professional Development. In C. Day, \& J. Sachs (Eds.), International Handbook on the Continuing Professional Development of Teachers (pp. 3-33). Open University Press.

Fullan, M. (2016). The New Meaning of Educational Change (5th ed.). Teachers College Press.

Gall, M. D., Borg, W. R., \& Gall, J. P. (1996). Educational Research: Am Introduction (6th ed.). Longman Publication.

Guskey, T. (2000). Evaluating Professional Development. Corwin Press, Inc. 
Leedy, P. D., \& Ormrod, J. E. (2001). Practical Research: Planning and Design. Merrill, Practice Hall.

Maslowski, R. (2001). School Culture and School Performance: An Explorative Study into the Organizational Culture of Secondary Schools and Their Effects. University of Twente Press.

Sikes, J. P. (2013). Imposed Change and the Experienced Teacher. In M. Fullan, \& A. Hargreaves (Eds.), Teachers Development and Educational Change (pp. 36-55). Routledge.

Swafford, J. (2000). Teachers Supporting Teachers through Peer Coaching. Support for Learning, 13, 54-58.

Ucana, S. (2016). The Role of Continuous Professional Development of Teachers in Educational Change: A Literature Review. Harran Education Journal, 1, 36-43.

https://doi.org/10.22596/2016.0101.36.43 


\section{Appendices}

\section{Appendix A: Survey Questionnaire}

Instructions: For each assertion, circle the number that closely expresses your consideration. The approval level is increased from 1 to 5.

\section{Instructions}

For each question, circle the number that roughly indicates your approval. Your approval indicates what you consider professionally right.

\begin{tabular}{ccccc}
\hline 1 & 2 & 3 & 4 & 5 \\
\hline Least approved & Almost less approved & Neutral & High approval & Higher approval \\
\hline
\end{tabular}

What is the impact of in-service training of primary school teachers on student achievement or outcomes?

1) Continuing professional development is essential for my career.

$\begin{array}{lllll}1 & 2 & 3 & 4 & 5\end{array}$

2) Ongoing professional development for teachers helps improve student achievement.

$\begin{array}{lllll}1 & 2 & 3 & 4 & 5\end{array}$

3) Continuous professional development gives teachers the opportunity to be up to date with new technologies.

$\begin{array}{lllll}1 & 2 & 3 & 4 & 5\end{array}$

4) Continuing professional development allows teachers to hone knowledge not learned during training.

$\begin{array}{lllll}1 & 2 & 3 & 4 & 5\end{array}$

5) Continuous professional development teaches teachers professional practices to make them continually competent.

$\begin{array}{lllll}1 & 2 & 3 & 4 & 5\end{array}$

6) Continuing Professional Development increases teachers' motivation, confidence and commitment to teaching.

$$
\begin{array}{lllll}
1 & 2 & 3 & 4 & 5
\end{array}
$$

7) Effective professional development (PEP) is essential to learning and developing the pedagogies needed to teach these skills.

$$
\begin{array}{lllll}
1 & 2 & 3 & 4 & 5
\end{array}
$$

8) Continuing professional development is program-based that focuses on teaching strategies associated with specific curriculum content that supports teacher learning in the context of classroom teachers.

$\begin{array}{lllll}1 & 2 & 3 & 4 & 5\end{array}$

9) Active learning directly engages teachers in designing and testing teaching strategies, giving them the opportunity to engage in the same learning style 
they design for their students.

$\begin{array}{lllll}1 & 2 & 3 & 4 & 5\end{array}$

10) High-quality professional development creates a space where teachers can share ideas and collaborate in their learning, often in contexts that are integrated into employment.

$\begin{array}{lllll}1 & 2 & 3 & 4 & 5\end{array}$

11) Continuing professional development gives teachers opportunities to view templates that include lesson plans, unit plans, student work examples, peer teacher observations, and video or written teaching cases to immerse themselves in a clear vision of what best practices look like.

$\begin{array}{lllll}1 & 2 & 3 & 4 & 5\end{array}$

12) Through continuing professional development, teachers benefit from expert assistance and support that involves sharing expertise on evidence-based content and practices, focused directly on the individual needs of teachers.

$\begin{array}{lllll}1 & 2 & 3 & 4 & 5\end{array}$

13) High-quality professional learning often allows teachers to reflect, receive feedback, and make changes to their practice by facilitating reflection and soliciting feedback.

$\begin{array}{lllll}1 & 2 & 3 & 4 & 5\end{array}$

14) Continuous and effective professional development gives teachers sufficient time to learn, practice, implement and reflect on new strategies that facilitate changes in their practice.

$\begin{array}{lllll}1 & 2 & 3 & 4 & 5\end{array}$

15) In my school, we practice the 14 points set out above quite often.

$\begin{array}{lllll}1 & 2 & 3 & 4 & 5\end{array}$

What is the cost associated with in-service teacher training?

16) At my school, we have opportunities for continuing professional development

$\begin{array}{lll}\text { every school year } & \text { Yes } & \text { No } \\ \text { every two years } & \text { Yes } & \text { No } \\ \text { Every five years } & \text { Yes } & \text { No }\end{array}$

17) My school believes that professional development for teachers

$\begin{array}{lcc}\text { would cost too much } & \text { Yes } & \text { No } \\ \text { would require qualified consultants } & \text { Yes } & \text { No }\end{array}$

18) High cost of continuing professional development for teachers discourages initiative

Yes $\quad$ No 
19) Is the continuous professional development of teachers essential for the teaching career? Please respond according to your position.

\begin{tabular}{|c|c|c|c|c|c|c|c|c|}
\hline \multirow{2}{*}{$\begin{array}{l}\text { Principal } \\
\text { Teacher }\end{array}$} & & & & \multicolumn{3}{|c|}{ Yes } & \multicolumn{2}{|l|}{ No } \\
\hline & & & & Yes & & & No & \\
\hline Circle the class level taught: & K & 1 & 2 & 3 & 4 & 5 & 6 & \\
\hline Your seniority in teaching: & $1-$ & & & $6-$ & $10 \mathrm{y}$ & & & 11 - 15 years; \\
\hline
\end{tabular}

